\section{In the eye of the beholder}

\section{J. Anthony Movshon}

Vislon: Coding and Efficiency. Edited by Colin Blakemore. Cambridge University Press: 1991. Pp.448. £65, \$120.

IN a scientific career spanning five decades, H. B. Barlow - one of the seminal figures in modern sensory physiology - has contributed extensively both to our understanding of visual processing and to the way in which we conceptualize the brain's representations of sensory information. Vision: Coding and Efficiency - a tribute to Barlow derives from a symposium held in Cambridge in 1987 to celebrate his 65 th birthday and his concurrent retirement from his Royal Society professorship, if not his retirement from science (he remains active today). Edited by Colin Blakemore, Barlow's first student, this handsomely produced book spans the extraordinary range of fields in which Barlow has made his presence felt.

The range of topics represented is both the strength and the weakness of the undertaking. Unlike many festschriften for lesser figures, which tend to collect too many papers devoted to a narrow subfield, this effort has a broad coverage of many areas of modern visual science, from fundamental optics, psychophysics and neurophysiology through conceptual models of image understanding. The result is almost the skeleton of a textbook of visual science. The only difficulty is that the coverage is so broadly based on the interests of those who have been associated with Barlow over the years that it is inevitably a bit uneven.

Nonetheless, there is much to treasure. The roster of authors is a distinguished one indeed, and a surprisingly large proportion have produced papers that are not simply minor revisions of their standard 'canned'

\section{Pulitzer Prize}

This year's Pulitzer Prize for general nonfiction has been won by zoologists Bert Höldobler of the University of Würzburg and Edward $\mathrm{O}$. Wilson of Harvard University for their monumental work The Ants.

The book, which was published in 1990 by Harvard University Press and Springer, runs to an astonishing 745 pages, has over 1,000 figures and includes all aspects of ant biology, evolution and ecology, with an emphasis on the reasnns underlying the success and importance of the group. According to Donald Feener, Diane Davidson and Jon Seger who reviewed the book in these pages (see Nature 344, 894-895; 1990), "Only Hölldobler and Wilson could have written such a comprehensive and integrated treatment of ant biology. It represents a herculean labour of love, and it sets a new standard for synthetic works on major taxa." review article. Notable among these are D. G. Pelli's lead chapter on quantum efficiency, which lays out an elegant framework (owing much to Barlow) for understanding the concept of statistical efficiency as applied to vision. D. Kersten's chapter is a brave effort to extend this kind of concept to higher-level processes of image understanding. Other papers on various aspects of spatial vision, light and dark adaptation, and colour vision, all add to a satisfying and coherent group of readings on the analysis of visual function by psychophysical techniques.

Coverage of visual neurobiology and development is a bit patchier. The book contains an intriguing mixture of papers on comparative topics (noteworthy and elegant are contributions by J. D. Pettigrew on stereopsis and by M. F. Land on compound eyes), on retinal function and organization (among them an appealing but stylistically dissonant piece on retinal heterogeneity by D. I. Vaney and A. A. Hughes), and on cortical processing (among them useful developmental papers by C. Blakemore and by R. C. Van Sluyters and his colleagues, and an extensive review of recent work on cortical architecture by S. M. Zeki). Because this part of the collection seeks to cover a vast and growing field, however, it leaves open rather more gaps than it fills.

\section{The bare bones}

\section{S. Mann}

Skeletal Blomineralizaton: Patterns, Processes and Evolutionary Trends. Volumes I and II. Edited by J. G. Carter. Van Nostrand Reinhold: 1991. Pp.1032. $\$ 99.95, £ 79$.

IF you were choosing a book to slip into your briefcase intending to pull it out again during a long international flight to an annual conference, it would not be Skeletal Biomineralization, Processes and Evolutionary Trends edited by Joseph Carter. For a start, at over 1,000 pages, the book would make a large hole in your baggage allowance. More importantly, reading a book like this is a serious matter.

The book is big in every way, and I have to say that I find the editor's dedication to producing this tome as awe-inspiring as the subject matter itself. The book comes in two volumes. The first 600 pages of volume I contains 25 invited chapters overviewing the mineralogy and microstructure of calcified skeletal tissues. The scope of these chapters vary enormously; the first nine contributions are relatively short (8-15 pages) and cover various aspects of biomineralization including general mechanisms, biomechanics, and calcification in spicules, corals, sponges, arthropods and gastropods, for example. Chapters 10-16 are written by the editor and are concerned with shell microstructure over 270 pages of immense detail. There-
Many of Barlow's most enduring contributions have been theoretical, and theory has its place here to. Again one might quibble at some unevenness and eccentricity; A. B. Watson's alarmingly crystalline concept of visual cortical processing stands out as a provocative effort in a slightly mundane set of chapters, as does Barlow's own contribution, a characteristically thoughtprovoking piece on the basis for visual aftereffects.

It is a little hard to decide for whom this book is best suited. It has many strong chapters, especially on psychophysical topics, and these form a state-of-the-art coverage of an important part of the field. In other areas, things are more scattered, so that the book as a whole cannot be endorsed for an audience seeking a full general treatment. But that would be a great deal to ask of any volume of this sort. Perhaps the ideal reader of the book has the intellectual breadth and curiosity of Barlow himself, and the same inclination to absorb concepts and ideas from a looselyknit but often fascinating collection of disciplines.

J. Anthony Movshon is at the Centerfor Neural Science, New York University, 6 Washington Place, 8th Floor, New York, New York 10003 , USA.

after, several shorter overviews, on subjects such as protochordate biomineralization, vertebrate skeletal tissues, dental structures and geology and related applications of isotopes, trace elements and amino acids, widen the perspective.

But all is not finished; another 200 pages including a glossary and a bibliography come before the index. The bibliography must rank as the best ever collated in this field. It is over 100 pages long and includes its own index. Volume II is more modest in size and provides supplementary illustrations, mainly in the form of photographs, of the skeletal structures discussed in volume I. The quality of production of electron micrographs, like that in volume $I$, is first class.

I was very impressed by this book. The work is scholarly and it is a mark of real scientific endeavour. Although the subject matter is very specialized, being at the more geological end of biomineralization, I recommend that chemists, materials scientists and biologists look at this book. The electron micrographs of volume II testify to the sophistication of biological processes to synthesize and assemble inorganic materials that would be termed smart in other more fashionable disciplines. This is a vast unexplored area and this book will be a valuable contribution not only in the detailed classification of skeletal structures but as a source of wonder and inspiration to scientists interested in the possibilities of mimicking biological materials in the laboratory.

S. Mann is at the School of Chemistry, University of Bath, Bath BA2 7AY, UK. 